\title{
The Role of Leisure Sports in the Construction of Harmonious Society from the Perspective of Well-off Society
}

\author{
Peipei Yang ${ }^{1}$ \\ ${ }^{1}$ Department of Physical Education, Oxbridge College, Kunming University of Science and \\ Technology, Kunming, Yunnan Province, China
}

Keywords: leisure sports; well-off society; harmonious society; health; people-oriented.

\begin{abstract}
Through literature review and comprehensive analyses, it is concluded that leisure sports can improve people's life styles, change their life conceptions, cultivate their fitness habits, and keep their body healthy and fit figures. They also play a positive role in building harmonious society, and promote the improvement of people's life quality.
\end{abstract}

\section{Introduction}

In modern society, the culture of mechanization, modernization, informatization and electrification degrades people's biological functions. High nutrition food and low consumption of energy cause fat accumulation. Fast rhythm and high pressure of life damage human's mental health. High technology and fast rhythm of life make people ignore emotional communication. People become indifferent and impetuous. Modern sports become a professional occupation, and go away from normal citizens. The original mass sports with the purpose of physical exercise are unable to meet the growing spiritual and cultural needs from citizens. Now people are pursuing for vigorous, high quality life and the realization of life value. All these phenomena call for a kind of public activities which is more effective and more suitable for modern men. Leisure sports can realize humanistic care, promote the sustainable development of sports, reduce social pressure and promote social harmony. Leisure sports can help people to find their lost spiritual home, and bring peace and harmony to the society.

\section{A Harmonious Society Needs Leisure Sports}

People need leisure sports. Along with the great improvement of material life, people's concepts are changing. Now citizens have more leisure time, and they begin to pay more and more attention to the quality of life and humanistic care. As a positive, healthy and civilized modern life style, leisure sports are becoming more and more important. What are leisure sports? The author thinks that "leisure sports are organized or individual activities which can set participants free from external pressure, improve their health conditions, and bring them mental satisfaction and social relations" . Their purpose is to improve people's mental and physical health, and bring vigor to the life of individuals. Leisure sports are related to interests of human beings and the realization of humanistic care. Their aim is to meet the physical and spiritual needs of high quality lives. Thus, doing leisure sports is an active and healthy life style which modern people are pursuing. Chinese sports industry has been influenced by the spirit of military nationalism. For a long time, it ignores the concept of humanism, suppresses individuals' personalities and human nature. When sports conception focuses on human nature, personality and entertainment, we will inevitably feel unfamiliar, confused and overwhelmed embarrassment. The lack of humanistic spirit is the biggest obstacle in the sustainable development of sports industry, and may cause potential crisis to social development. In the new century, we have the best opportunity in history to advocate humanistic spirit, bring it to sports theory, and combine sports practice with leisure entertainment under the guidance of "people-oriented" principle [1]. Chinese competitive sports industry should weaken its image of political tools, and become the carrier of health and entertainment for every Chinese citizen. At one time, ball games are always link to the power of our country, so many people look forward to "win” , and only pay 
attention to the result. Emotional experiences during the game are ignored. Now people are more inclined to pay more attention to watching wonderful performances. For football fans, they are looking for spiritual pleasure. These are leisure sports, which can not only improve people's way of life, but also cultivate their sports awareness and values, as well as aesthetic taste of life.

Leisure sports can achieve humane care and avoid disadvantages brought by modern science and technology. Due to the promotion effects of economy and high technology on the development of society, the development of sports industry has been depended on two foundations: economy, as well as science and technology. The former determines the scale and level of China's sports industry, the latter determines the quality and efficiency of China's sports industry. The prevalence of this concept leads to the extreme scientism, which prevents common citizens from enjoying the happiness of sports, and brings many problems to their leisure life. It is not conducive to the development of extensive mass fitness programs, nor the improvement of national quality and social stability. While leisure sports start from persons' abilities and interests, encourage people to enjoy the fun of sports, and cultivate people's sports consciousness. With the development of leisure sports, more and more people will join in sports activities, and spend their leisure time in civilization, health and happiness; more and more sports talents will become professional athletes, while athletic events will become "toys" of the civilized society, which can meet the spiritual and cultural needs of people. When there are more and more toys on the sports field, people will be actively involved in sports, which will guarantee the permanent development of sports industry [2]. Free and joyful citizens are essential for social stability and harmony.

\section{Leisure Sports Meet the Needs of the Harmonious Development of People}

People can benefit from participation. Engels believes that people's needs are divided into three levels: the needs of survival, the needs of entertainment and enjoyment, and the needs of development. As a part of science, leisure sports can satisfy people's needs of survival by protecting their health and prolonging their life span; as a part of culture, leisure sports can satisfy people's needs of entertainment and enjoyment by encourage them to voluntarily participate in sports activities and watch various competitions; as a part of education, leisure sports can meet people's needs of development.

American scholar John Kelly holds that, leisure should be understood as a process of "being a person" . It is one of the main existence spaces for personal and social development; it is a lasting and important stage in people's lives. Leisure sports help people to obtain the effects of sports in leisure and entertainment. The new concept of human value means that, the change of nature in history will gradually become the change of human being. People want to live with ease, peace, harmony and simplicity [3].

The foundations of leisure sports are relaxation, happiness, excitement and comfort. Through leisure sports, people in the fast-paced and highly competitive world can easily go into the realm of leisure. People do not pursue economic success anymore; participation means happiness, success, joy and peace. Leisure sports are not designed process, but random activities which can satisfy people's interests, encourage them to create personalized innovations, enjoy the fun of sports, and realize physical and mental relax. The development of leisure sports is a cultural phenomenon which related to social progress and human civilization.

Leisure sports meet the needs of the vast majority of people. With the development of our society and the popularization of school education, most people in China have received physical education, watched sports performances, grasped basic sports skills and sports knowledge. They cannot accept sports with special physical and technical requirements easily, but they have influenced by the exciting sports movement. What they need is physical activities combined with entertainment [4]. Leisure sports start from human nature, trying to meet the needs of people's interest and achieve the construction of individual spirit. They promote self perfection and development, and can meet the growing physical and spiritual needs of people. 
Entertainment at multiple levels. In the realization of humanistic care, leisure sports adhere to the people-oriented principle; they insist on voluntary participation, optional sports activities, and the flexibility of activity time. They can meet different needs of people from many aspects by building people's physical bodies, soothing their psychological feelings, and providing them with aesthetic experience. Leisure sports activities are more various and exciting. They can meet the needs of people from different groups and at different ages. They start from personal interests, and pursue the harmonious development of people and the society [5]. For people who want to stay away from the noisy cities and return to nature, and who want to relax from stress, leisure sports are perfect choices.

\section{Leisure Sports meet the Needs of Harmonious and Sustainable Development of Modern Society}

Promoting social interaction. Social harmony means all social subsystems and elements are interdependent, mutual coordinated and mutual promoted. Dr. Xiao-peng Ren from Chinese Academy of Sciences Institute of Psychology believes that in a harmonious society, in addition to the harmony between individuals, the harmony between individual and the community is also needed [6]. The vitality of a socialist society is not only reflected in the economic, political, cultural and other aspects, but also reflected in the perspective of citizens. The motive force of the development of the socialist society is manifested in the full play of initiation, enthusiasm and creativity of social members. However, in today's society, the high degree of mechanization and fast-paced, high pressure life make people ignore human interaction and emotional communication. Leisure sports can create a relaxed, friendly and pleasant communication environment for people. They make strangers become familiar, acquaintances become more closely. The common hobbies can bridge the gap, and increase emotional communications between family members, neighbors and colleagues. Through collective activities, all relations can be peaceful and joyful. They help to create warm, comfortable and friendly family lives, work environments and social environments, and improve the quality of life. Only under the relaxed and harmonious atmosphere, can we fully mobilize the enthusiasm of people, and provide strong motivation to support all kinds of works.

Maintaining social stability. Leisure sports can make timely adjust and relax citizens from the busy work and family life, and avoid hazardous events like drunkenness, fighting and gambling. They can also enrich people's leisure life, reduce serious social problems, and maintain social security and stability. As a result, social members in the peaceful environment will be full of creative energy. After recovering from physical and mental sufferings, they will be able to try their best to play their roles in the society. A kind of positive and beneficial social harmony will be created [7].

Expanding employment, stimulating economic growth. With the development of society and the improvement of people's living standard, leisure sports industry has become a hot industry. Increasing amount of money has been invested in medium-sized golf courses, race courses, ski fields, gyms, basketball courts, badminton halls, as well as chess and card rooms. A lot of guidance and service personnel are needed in the construction of recreational sports field, which effectively solve the employment needs, and reduce disharmonious factors in the development of modern society.

\section{Leisure Sports Meet the Needs of Sustainable Development of National Fitness}

The sustainable development of national fitness can be achieved under the condition of people's consciousness. How to mobilize people to consciously engage in fitness activities? Leisure sports provide people a platform of becoming themselves. In order to guide leisure time to leisure sports activities, we must pay attention to leisure sports education first. Leisure physical education is a kind of educational activity available to all. Only the participation of the majority of people can play a positive effect during this process, and promote the healthy development of society. 


\section{Conclusions}

With the vigorous development of China's sports industry, we need to promote leisure sports to the public. They are beneficial to harmonious and comprehensive development of the society, and the improvement of peoples' healthy levels. It is conductive to the communication and understanding between members of society; it can build a stage for the quality education of students; it can reduce the crime rate in society, and maintain social security and stability; it can create more employment opportunities, narrow the income gap between social members, and promote economic growth. Therefore, it is of great practical significance in building the socialist harmonious society of China.

\section{References}

[1] J.C. Chen, The role of leisure sports in building a harmonious socialist society, J. Journal of Beijing Sport University. 30 (2007).

[2] G.X. Ma, Harmonious society sports should benefit all citizens, J. Journal of the Chinese People's Political Consultative Conference. Nov. 25, 2005

[3] J. Zhao, X.Z. Zhai, S.L. Liu, Construction of a well-off society in all-round way and the construction of leisure sports culture ecosystem, J. Journal of Sports and Science. 27 (2006).

[4] Z.X. Xu, Leisure: pursuit of the value of life in a new historical starting point, J. Journal of Guangzhou Sport University. 6 (2007).

[5] L.J. Shi, leisure sports and healthy life style, J. Guizhou Sports Science and Technology. 1 (2007).

[6] J. Yu, L.L. Xia, Harmonious society and leisure sports, J. Guizhou Sports Science and Technology. 1 (2007).

[7] Q.H. Liu, Discussion on concepts of leisure sports and harmonious society, J. Journal of Sports and Science. 27 (2006). 